\title{
England, US report sepsis successes
}

\author{
Cite as: CMAJ 2017 October 30;189:E1348-9. doi: 10.1503/cmaj.109-5509
}

Posted on cmajnews.com on Oct. 11, 2017.

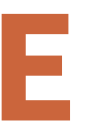

ngland and the United States have become early leaders in the global fight against sepsis after tragic cases brought a new spotlight to gaps in care, experts shared at a recent international congress hosted by the World Health Organization and Global Sepsis Alliance.

"Sepsis is a huge problem with six million lives claimed every year," said Dr. Ron Daniels, chief executive of the United Kingdom Sepsis Trust. The life-threatening condition arises when the body's response to infection damages its own tissues and organs. But despite being a leading cause of death and disability, sepsis is often overlooked and underreported.

A 2014 review of sepsis cases in England found that $80 \%$ of patients already had underlying infections and more than half were septic by the time they sought care, said Daniels. "We estimate we can save 14000 lives just by heightening public awareness."

In both England and the US, efforts to improve awareness and provide timely treatment for sepsis were spurred by the preventable deaths of children.

At first, the UK Sepsis Trust focused its advocacy efforts on government. But then one-year-old William Mead died of sepsis from a chest infection just before Christmas 2014. "William's mom had made 21 separate calls to the health system, all of which were largely ignored," said Daniels. "The media went crazy over William," and the campaign shifted its focus. "We learned that working with the media was the key to engaging the public."

That included working with the tabloid press - the Daily Mail declared "all-out war on sepsis" - in addition to other news outlets, Daniels noted. "We have to engage different demographics."

As a result of the media attention, England's health minister became a cham-

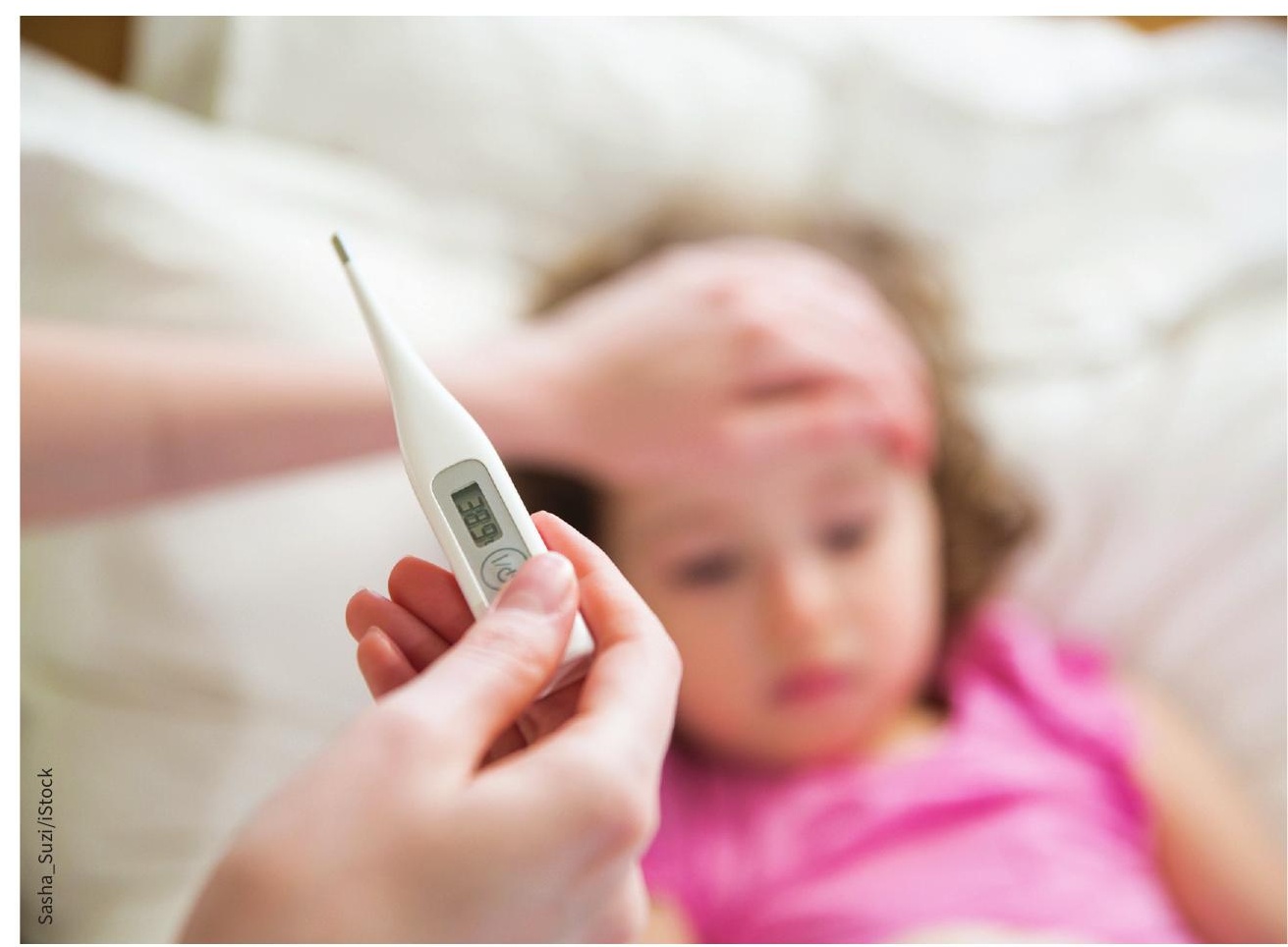

Spurred by preventable deaths, action on sepsis is starting to pay off.

pion of the campaign. The National Health Service sent warnings about the signs of sepsis to parents of newborns and issued more than one million posters reminding the public to "think sepsis" in cases of infection.

The campaign also harnessed "free advertising," requesting donations of ad space from television and signage companies, and displaying messages about sepsis on ambulances and community doctors' cars. In one case, the producers of a weekly medical soap opera with 5.1 million viewers displayed posters about sepsis in the main scenes of 13 episodes.

Before the campaign, two in five people in England had heard of sepsis; now that number is closer to three in four. Among those who are aware of the condition, $75 \%$ know it's a medical emergency.
The number of recorded sepsis cases also increased four-fold, suggesting improved recognition and diagnosis. Importantly, health services didn't see an increase in traffic of the "worried well," said Daniels. The campaign shows that it's possible to achieve improvements, even without "millions of euros to conduct a traditional awareness campaign," he said. Other countries may focus on different messages or mediums, but "the basis of communication saving lives can be translated across every country."

While England focused on educating the public to seek care sooner, an initiative in New York State has targeted hospitals following the death of 12-year-old Rory Staunton in 2012.

Despite showing signs and symptoms of sepsis from an infected cut, Rory was 
misdiagnosed with a stomach virus, and repeatedly discharged from hospital, even as he deteriorated.

In response to public outcry, New York State required all hospitals to develop protocols for screening patients, as well as guidelines for timely sepsis care. Other states are launching similar initiatives and the US Centers for Medicare and Medicaid now publicly report on sepsis care performance.

Between 2014 and 2016, identification of patients with sepsis in New York State increased $20 \%$ and sepsis deaths in adults steadily declined, from $30.2 \%$ to $25.4 \%$. The percentage of children who received all recommended early treatments within one hour more than tripled from $4.9 \%$ to $17.6 \%$, and the percentage of adults who received appropriate care within three hours increased from $41.5 \%$ to $55.2 \%$.

As yet unpublished data show "really compelling evidence that compliance with the performance measures is associated with improved survival," said Dr. Mitchell Levy, professor of medicine and division chief of pulmonary and critical care medicine at Brown University. A recent study in the New England Journal of Medicine also found that every hour of delay in initiating the protocols was associated with a statistically significant increase in mortality.

"This shows we can make a difference in these patients with severe sepsis and septic shock," Levy said. "We can change clinical behaviour and we can make a difference in survival."

Lauren Vogel, CMAJ 